\title{
The impact of antiandrogen flutamide on the hypoxia inducible factor $1 \alpha$ and vascular endothelial growth factor $A$ gene and protein expression in the pig placenta during late pregnancy
}

\author{
Elzbieta Czaja ${ }^{1}$, Iwona Wieciech-Rojkiewicz ${ }^{1}$, Katarzyna Knapczyk-Stwora ${ }^{1}$, \\ Malgorzata Grzesiak ${ }^{2}$, Maria Slomczynska ${ }^{1}$
}

${ }^{1}$ Department of Endocrinology, Institute of Zoology and Biomedical Research, Jagiellonian University in Krakow, Poland

${ }^{2}$ Department of Animal Physiology and Endocrinology, University of Agriculture in Krakow, Poland

\begin{abstract}
Introduction. In contrast to estradiol action, little is known about androgen signaling in placental development. The purpose of this study was to evaluate the impact of diminished androgen action on hypoxia inducible factor $1 \alpha(\mathrm{HIF}-1 \alpha)$ and vascular endothelial growth factor A (VEGFA) protein expression as well as their mRNAs in the structures of fetal and maternal parts of porcine placenta during late pregnancy.

Material and methods. Pregnant pigs were injected daily with antiandrogen flutamide, at a dose of $50 \mathrm{mg} / \mathrm{kg}$ body weight at different stages of pregnancy: between gestational days 83-89 (90 dpc) and 101-107 (108 dpc). Control groups ( $90 \mathrm{dpc}$ or $108 \mathrm{dpc}$ ) were treated with vehicle (corn oil). One day after the last injection animals were sacrificed and tissues were collected. Tissue samples were frozen for mRNA isolation or fixed for immunohistochemistry (IHC). The expression of HIF- $1 \alpha$ and VEGFA were investigated by real-time PCR and IHC. Results. Flutamide treatment caused changes in both HIF- $1 \alpha$ and VEGFA mRNA levels only in the placentas of the $90 \mathrm{dpc}$ group. Relative optical density analysis showed decreased HIF- $1 \alpha$ and increased VEGFA protein expression in the placentas obtained from flutamide-treated $108 \mathrm{dpc}$ group while no differences were observed in the $90 \mathrm{dpc}$ group.

Conclusions. Experimentally induced androgen deficiency in pigs deregulates the expression of some genes important for placental blood circulation. We suggest that androgens are involved in the control of expression of HIF-1 $\alpha$ and VEGFA in porcine placenta during late pregnancy. (Folia Histochemica et Cytobiologica 2017, Vol. 55, No. 3, 159-167)
\end{abstract}

Key words: VEGFA; HIF-1 $\alpha$; androgens; flutamide; placenta; pig; IHC; QPCR

\section{Introduction}

Nutritional, metabolic and endocrine components present in the placental blood circulation are delivered from mother to the developing fetus. Therefore,

\footnotetext{
Correspondence address: Prof. M. Slomczynska, PhD Department of Endocrinology Institute of Zoology and Biomedical Research Jagiellonian University in Krakow Gronostajowa 9, 30-387 Krakow, Poland e-mail: maria.slomczynska@uj.edu.pl
}

a properly developed placental vascular network is indispensable to meet all requirements regarding transfer of oxygen and all essential nutrients. The demands of developing fetuses as well as environmental signals cause dynamic functional changes within placenta. Multiple factors, including steroid hormones and growth factors, are involved in the regulation of placental angiogenesis [1]. The uterine vascular tone has been regulated by progesterone and estrogens. The formation of new blood vessels which occurs in the placenta during early pregnancy is known to be regulated by progesterone [2]. Estrogens, which are 
locally produced by $\mathrm{P} 450$ aromatase within stromal uterine cells, seem to be involved in neovascularization, by increasing the expression of hypoxia inducible factor $2 \alpha$ (HIF-2 $\alpha$ ) [3]. Among many other functions assigned to estradiol is the induction of the expression of the vascular endothelial growth factor (VEGF) protein in the cytotrophoblast and the increase in vessel density of placental tissue which was observed in many species, including human [3,4]. Mast cells, which are attracted to the uterus by estradiol and progesterone, secrete substantial amounts of VEGF, suggesting a role of inflammation in the placental angiogenesis [5].

Although androgens are considered typically male hormones they are also important for the female reproduction in various mammalian species $[6,7]$. Androgens acting through their receptors (ARs) are involved in the formation of the placenta, trophoblast differentiation and the creation of new blood vessels. The presence of ARs has been demonstrated in the trophoblast cells of many species including human [8], pig [9], and cow [10].

The hypoxic environment of the first trimester is believed to play an important role in the regulation of trophoblast differentiation [11]. One of the transcription factors activated during low oxygen $(<5 \%)$ conditions is HIF- $1 \alpha$, a heterodimeric transcription factor, composed of two subunits, the HIF- $1 \alpha$ (or its analogs HIF- $2 \alpha$ and HIF- $3 \alpha$ ) and HIF- $1 \beta$. Under normal oxygen tension, HIF- $1 \alpha$ protein expression is negatively regulated by proteasomal degradation and ubiquitination [12]. However, HIF- $1 \alpha$ can be also regulated by oxygen-independent factors such as hormones, cytokines and growth factors [13]. HIF-1 $\alpha$, which is an important proangiogenic factor, exerts its role by transcriptional regulation of such factors as VEGF [14]. VEGF, a major regulator of angiogenesis which promotes endothelial cell migration toward a hypoxic area, plays a key role in placental growth and development [15]. Previously, we found that experimentally-induced androgen deficiency during the late gestational period led to increased expression of AR protein in pig placenta and changes in connexin 43 (Cx43) expression which may result in improper cell-to-cell communication and feto-maternal exchange [16]. Therefore, this study was undertaken to investigate the effect of androgen deficiency, induced by the administration of antiandrogen flutamide, on the expression of HIF- $1 \alpha$ and VEGF responsible for the proper development of new blood vessels in pig placenta.

\section{Material and methods}

Animals. All procedures were performed in accordance with the Polish legal requirements, under a license given by the Local Ethics Committee at the Jagiellonian University, Krakow, Poland (No. 122/2009).

The tissues were collected from crossbred pigs (Large White $\times$ Polish Landrace) at different stages of pregnancy. Pigs (12 animals) were mated with a fertile boar at the beginning of estrus phase, 12 and 24 hours after first mating. The day of first mating were admitted as a beginning of pregnancy. Breeding pigs were divided into 2 experimental groups with 3 animals $(\mathrm{n}=3)$ in each group ( $90 \mathrm{dpc}$, days post coitum, and $108 \mathrm{dpc}$ ) treated with flutamide (2-methyl-N-[4-nitro-3'-(trifluoromethyl)-phenyl]propamide) (Sigma-Aldrich, St. Louis, MO, USA). Control groups (90 dpc and $108 \mathrm{dpc}, \mathrm{n}=3$ each) were treated with vehicle (corn oil). Sows from first experimental and control groups $(90 \mathrm{dpc})$ were daily subcutaneously (s.c.) injected with flutamide at the dose of $50 \mathrm{mg} / \mathrm{kg}$ body weight or with corn oil, from 83 to 89 day of pregnancy. Similarly, second experimental and control groups (108 dpc) were administered flutamide or corn oil between 101 and 107 day of pregnancy. On the next day after the last s.c. injection pigs were anesthetized and placentas were collected as previously described. In short, pregnant gilts received atropine $(0.05 \mathrm{mg} / \mathrm{kg}$ b.w. $)$ and azaperone $(2 \mathrm{mg} / \mathrm{kg}$ b.w.) as a premedication. Once the sow were sedated (20-30 min later), anesthesia was induced by injecting thiopental $(10 \mathrm{mg} / \mathrm{kg}$ b.w.) to continuous infusion till deep aesthesia. The placentas were obtained from flutamide-treated and control pregnant gilts on $90 \mathrm{dpc}(\mathrm{n}=18$ and $\mathrm{n}=9$ placentas, respectively) or on $108 \mathrm{dpc}(\mathrm{n}=20$ and $\mathrm{n}=18$ placentas, respectively). Placentas were immediately excised, part of placenta was fixed in $10 \%$ buffered formalin for immunohistochemistry, while the other part was snap frozen in liquid nitrogen for RNA isolation and real time PCR analysis.

The time of flutamide administration was selected based on literature data [17], since androgens could have an effect in periods important for placentas and maternal-fetal connection development, in sows. In late pregnancy between 70 and $90 \mathrm{dpc}$ a significant increase in angiogenesis and placenta development is observed, whereas from $108 \mathrm{dpc}$ androgens had an effect on periparturient processes $[18,19]$.

RNA isolation and Real-time PCR analysis. Total RNA was extracted from collected pig placentas using the NucleoSpin RNA II System (Macherey-Nagel GmbH \& Co., Düren, Germany) according to the manufacturer's protocol. The quantity of total RNA was checked by measuring absorbance at 260 and $280 \mathrm{~nm}$ with a NanoDrop ND2000 Spectrophotometer (Thermo Scientific, Wilmington, DE, USA), whereas quality of RNA was verified by electrophoresis on a $1 \%$ formaldehyde-agarose gels. For reverse transcription we used $1 \mu \mathrm{g}$ of total RNA and a High-Capacity cDNA Reverse Transcription kit (Applied Biosystems, Carlsbad, CA, USA) according to the protocol provided by the manufacturer. Reverse transcriptase reaction mixtures were prepared in 
$20 \mu \mathrm{l}$ volume using the random primers, dNTP mix, RNAse inhibitor and MultiScribe reverse transcriptase. The reverse transcription was performed in a Veriti Thermal Cycler (Applied Biosystems) according to the following thermal profile: (1) $25^{\circ} \mathrm{C}$ for $10 \mathrm{~min}$, (2) $37^{\circ} \mathrm{C}$ for $120 \mathrm{~min}$, and (3) $85^{\circ} \mathrm{C}$ for $5 \mathrm{~min}$. Contamination of genomic DNA amplification was checked periodically by control experiments, in which reverse transcriptase was omitted during the RT step.

Real-time PCR was performed using the StepOne ${ }^{\mathrm{TM}}$ Real-Time PCR System (Applied Biosystems). The mRNA expression level of the HIF- $1 \alpha$ were quantified in each sample using TaqMan Gene Expression assays (assay ID: Ss03390447_m1; Applied Biosystems), VEGFA (assay ID: Ss033393993) with endogenous control for glyceraldehyde-3-phosphate dehydrogenase (GAPDH; assay ID: Ss03373286_u1) according to the manufacturer's instructions. The amount of each target cDNA was normalized with respect to the GAPDH ( $\Delta$ Ct value) as previously described [20]. The relative expressions of HIF- $1 \alpha$ and VEGFA were presented as $2^{-\Delta \mathrm{Ct}}$. These $2^{-\Delta \mathrm{Ct}}$ values were used to calculate statistical differences, using Statistica v. 10 program (StatSoft Inc., Tulsa, OK, USA).

Immunohistochemistry. Tissue samples for immunohistochemical localization of the HIF- $1 \alpha$ and VEGFA were washed in PBS and fixed in 10\% buffered formalin overnight. Then, samples were dehydrated in an increasing gradient of ethanol and equilibrated with xylene before embedding in Paraplast ${ }^{\circledR}$ wax (Monoject Scientific Division of Sherwood Medical, St. Louis, MO, USA). Tissue sections were cut at $5 \mu \mathrm{m}$ on a microtome and subsequently placed on slides, deparaffinized in xylene and rehydrated in decreasing gradient of ethanol. Antigenic epitopes were exposed by boiling sections in citrate buffer $(\mathrm{pH} 6.0)$ three times (2.5 min each) in a microwave. After 30 min cooling, activation of endogenous peroxidase was blocked by $0.3 \% \mathrm{H}_{2} \mathrm{O}_{2}$ in TBS (Tris buffered saline, $\mathrm{pH}$ 7.4) for $20 \mathrm{~min}$. Next, sections were incubated for $30 \mathrm{~min}$ at room temperature with $10 \%$ normal horse serum (NHS; samples for HIF-1 $\alpha$ ) or $10 \%$ normal goat serum (NGS; samples for VEGF) to block non-specific antibody-binding sites.

For immunodetection, samples were incubated $\left(4^{\circ} \mathrm{C}\right.$, $\mathrm{O} / \mathrm{N}$ ) with the primary polyclonal goat anti-HIF- $1 \alpha$ antibody (1:50, Santa Cruz Biotechnology Inc., Santa Cruz, CA, USA; sc-12542) or the primary polyclonal rabbit anti-VEGFA antibody (1:300, Santa Cruz Biotechnology Inc.; sc-152). After washing three times (5 min each) in TBST buffer, the secondary biotinylated horse anti-goat antibody (1:300, Vector Laboratories, Burlingame CA, USA) or goat anti-rabbit antibody (1:400, Vector Laboratories) were applied for incubation $(1.5 \mathrm{~h})$ in humidified chamber. Unbound secondary antibodies were removed by washing in TBST and sections were covered by avidin-biotin-horseradish peroxidase complex (ABC, 1:100, Vectastain ABC Kit, Vector
Laboratories) according to the manufacturer's instructions and incubated (40 min) in the dark. To visualize reaction product, DAB (3,3'-diaminobenzidine) was applied. Sections were stained with Mayer's hematoxylin or left unstained (for measurement of relative optical density). Finally, slides were dehydrated in the increasing gradient of ethanol, impregnated in xylene and mounted on DPX (Fluka Chemie GmbH, Buchs, Switzerland). Negative controls were performed by substituting the primary antibody with non-immune goat (for HIF-1 $\alpha$ ) or rabbit (for VEGFA) IgG.

The Nikon Eclipse E200 microscope with attached Nikon Coolpix 5400 digital camera system was used for taking photomicrographs. The intensity of immunoreaction was quantified by a videodensitometric analysis with Image J software (NIH, Bethesda, MD, USA) using digital images from at least seven different sections (not counterstained with hematoxylin) obtained from examined placenta. The intensity of HIF- $1 \alpha$ and VEGFA staining was expressed as a relative optical density (ROD) of DAB brown reaction products. It was calculated using the formula: $\mathrm{ROD}=\mathrm{Od}$ $/ \mathrm{Od}_{\text {background }}=\log \left(\mathrm{GL}_{\text {blank }} / \mathrm{GL}_{\text {specimen }}\right) \log \left(\log \mathrm{GL}_{\text {blank }} / \mathrm{GL}_{\text {specimen }}\right)$, where GL is the gray level measured after removing the slide from the light path [21].

Statistical analysis. All data are presented as the overall mean \pm standard error of the mean (SEM). Normal distribution of data was tested with the Shapiro-Wilk and Lilliefors test. Then, the nonparametric Mann-Whitney U-test was used to determine significant differences between the control and flutamide-treated groups. P level less than 0.05 was regarded as statistically significant.

\section{Results}

\section{Expression levels of HIF-1 $\alpha$ and VEGFA mRNAs}

The expression of HIF- $1 \alpha$ mRNA in the porcine placentas at $90 \mathrm{dpc}$ was down-regulated in the group treated with flutamide, compared to the control group $(\mathrm{p}<0.01)$. In the porcine placentas at $108 \mathrm{dpc}$ there were no statistically significant differences in mRNA expression between control and experimental groups (Fig. 1A).

The expression of VEGFA mRNA was examined in the porcine placenta on days 90 and 108 of pregnancy. Data shown in Figure 1B demonstrate that at $90 \mathrm{dpc}$ VEGFA mRNA level was lower than in the control group ( $\mathrm{p}<0.01)$. In the pig placentas at $108 \mathrm{dpc}$ no differences in the expression of VEGFA mRNA between experimental and control groups were found.

\section{Immunolocalization of HIF-1 $\alpha$ protein}

Immunohistochemical staining showed that HIF-1 $\alpha$ protein was present in various structures of placenta: chorionic epithelium (fetal part of placenta) and endometrial epithelium (maternal part of placenta). 


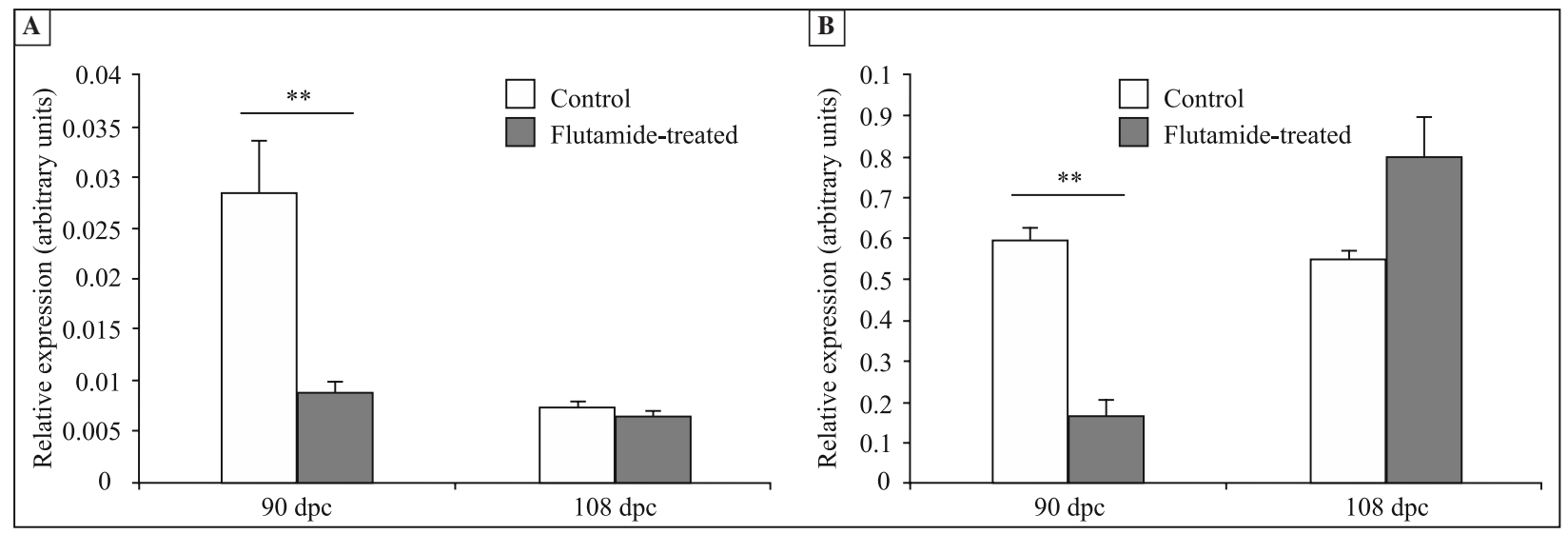

Figure 1. The expression of HIF-1 $\alpha$ mRNA (A) and VEGFA mRNA (B) in porcine placentas obtained from control and flutamide-treated pigs on day $90 \mathrm{dpc}$ and $108 \mathrm{dpc}$. The mRNA expression was determined using real-time PCR as described in Material and methods. Symbols: open bars — control, corn oil-treated pregnant pigs; solid bars — flutamide-treated animals. Statistically significant differences were analyzed by Mann-Whitney U-test $\left({ }^{* *} \mathrm{p}<0.01\right)$.

All of these structures demonstrated positive staining in control and experimental groups both after 90 and 108 days of pregnancy (Fig. 2A-D). HIF- $1 \alpha$ protein was localized in the cytoplasm of epithelial cells. Data obtained from 90 day of pregnancy do not show any relevant differences between control and experimental groups. In $108 \mathrm{dpc}$ porcine placentas the intensity of HIF- $1 \alpha$ immunostaining was significantly lower in flutamide-treated group compared to the control pigs $(\mathrm{p}<0.05)$ (Fig. 3A, A'). Moreover, in placentas collected from animals treated with flutamide, chorionic epithelial cells showed stronger staining compared to epithelial cells of the endometrium (Fig. 3A, A').

\section{Immunolocalization of VEGFA protein}

VEGFA cytoplasmatic immunostaining was observed in two cell types in the placenta - the chorionic epithelial cells and endometrial epithelial cells - both on 90 and 108 day of gestation (Fig. 2E-H).

Although in the chorionic epithelial cells the VEGFA protein showed a slight tendency to increase under flutamide administration at $90 \mathrm{dpc}$ and 108 $\mathrm{dpc}$, the differences in immunostaining intensity were statistically not significant (Fig. 3B, B').

In endometrial epithelial cells at $90 \mathrm{dpc}$ strong immunostaining was observed with slight decrease under flutamide influence (not significant). On the other hand at $108 \mathrm{dpc}$, flutamide treatment caused an increase in immunoreactivity of VEGFA $(p<0.05)$ in comparison to control (Fig. 3B').

\section{Discussion}

Our study revealed the presence of VEGFA and HIF$-1 \alpha$ mRNA and protein in the porcine placental com- partments on days 90 and 108 of pregnancy. We have demonstrated that their expression might be regulated by androgens, as the antiandrogen flutamide caused changes in the level of both mRNAs and proteins.

Several lines of evidence have indicated that the synthesis of VEGFA is regulated by HIF- $1 \alpha$, especially under hypoxic conditions [22]. On the other hand, VEGFA expression is also regulated directly by androgens as in the promoter of VEGFA gene the half-site for androgen response element (ARE) is present [23].

Many biological compounds, including steroid hormones (estrogens, progesterone and also androgens) are involved in the regulation of the female reproductive system [24].

The effect of testosterone cannot be easily separated from estrogenic effects, as in the placenta androgens are metabolized to estrogens by $\mathrm{P} 450$ aromatase. Nevertheless, animal models have shown that elevated androgen levels during pregnancy induce the downregulation of genes related to vascular development and angiogenesis in the placenta [18].

Our previous work demonstrated the presence of AR mRNA and protein in the porcine uterus throughout pregnancy from day 10 to 90 . AR protein was detectable in the glandular epithelium, stroma cells and myometrium in all investigated days of pregnancy; however, the intensity of staining declined during the studied period. The presence of AR mRNA was shown at the early pregnancy, while from $32 \mathrm{dpc}$ the transcript was not detectable [25].

To determine the role of androgens in the regulation of androgen-dependent genes in various tissues, ARs may be blocked by binding with flutamide, a non-steroidal antiandrogen compound [26]. We 


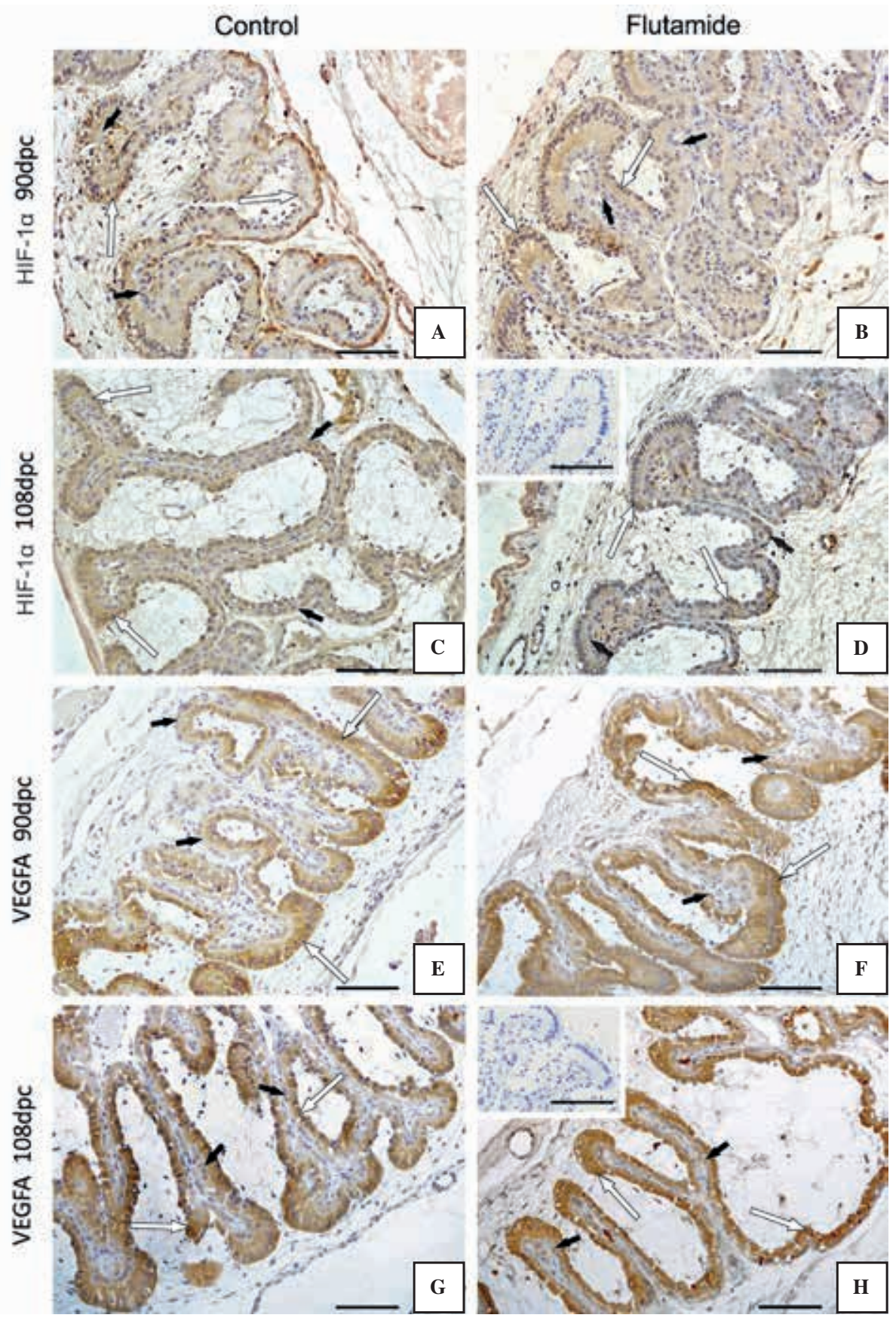

Figure 2. Immunohistochemical localization of HIF-1 $\alpha$ (A-D) and VEGFA (E-H) proteins in paraffin-embedded sections of the porcine placenta. Control animals (A, C; E, G) and flutamide-treated pregnant pigs (B, D; F, H) for 7 days at 90 dpc (A, B; E, F) and $108 \mathrm{dpc}(\mathrm{C}, \mathrm{D} ; \mathrm{G}, \mathrm{H})$. Negative control of staining: inserts in D and H. Symbols: white arrows - chorionic epithelial cells; black arrows - endometrial epithelial cells. Sections of placentas were stained as described in Material and methods. Scale bars: $100 \mu \mathrm{m}$.

have introduced such a model in several experiments performed on swine during late pregnancy. Our study revealed the presence of androgen receptor protein in trophoblast epithelial cells at the base of chorionic ridges [9]. The fact that AR was up-regulated in the tissues of animals injected with flutamide, shows that androgens are important hormones in the porcine reproductive system.
Increased maternal testosterone levels can act directly on the fetus causing its damage $[27,28]$ or indirectly on the circulation within uteroplacental units reducing blood flow [29]. Therefore, the rat pregnancy model with elevated testosterone level has been introduced recently. E.g. it was shown that elevated testosterone reduced uterine blood flow, spiral artery elongation, and placental oxygenation as 


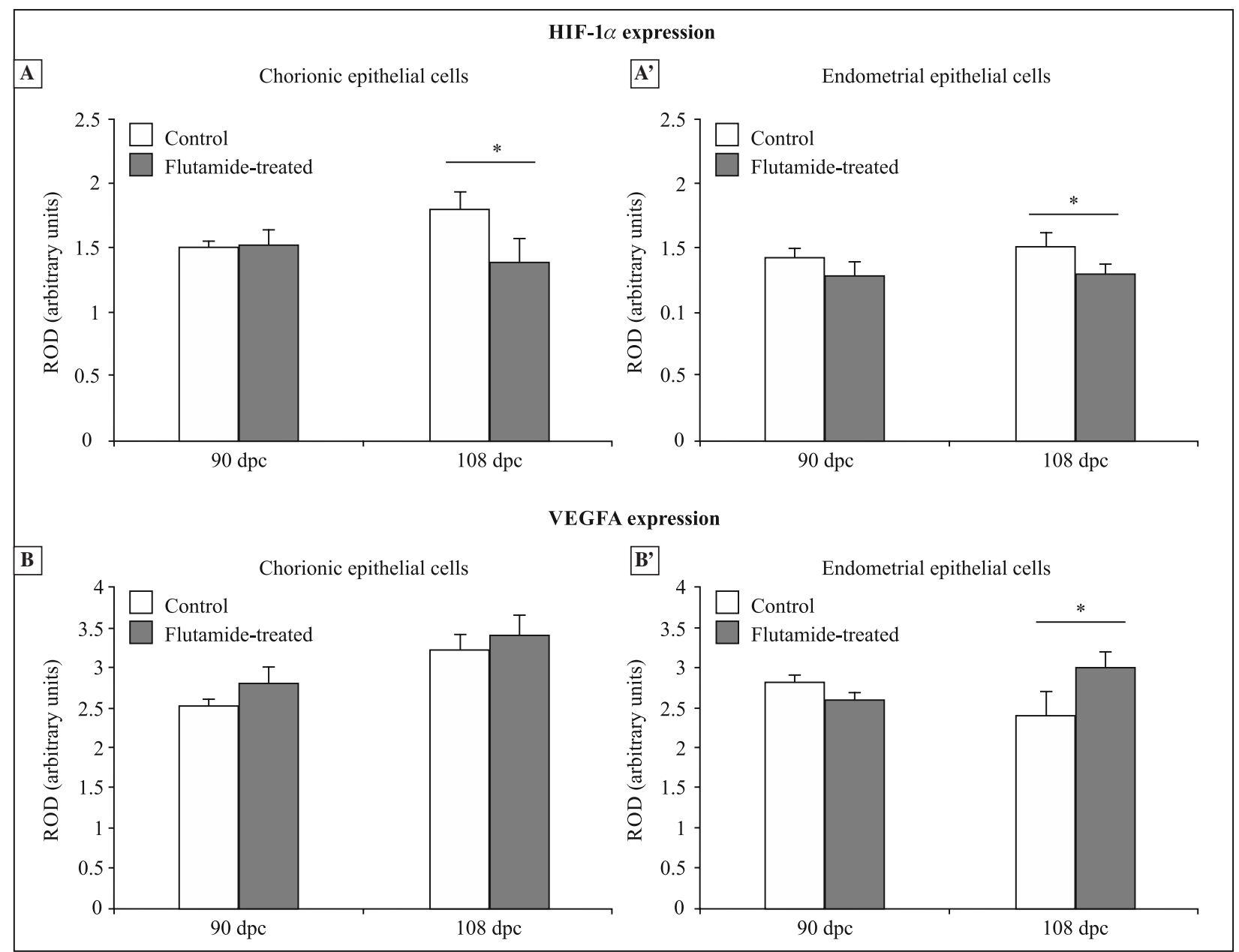

Figure 3. The intensity of immunohistochemical staining expressed as relative optical density (ROD) of diaminobenzidine (DAB) brown reaction products for HIF- $1 \alpha$ in chorionic epithelial cells (A) and endometrial epithelial cells (A') as well as for VEGFA in chorionic epithelial cells (B) and endometrial epithelial cells (B') of pigs exposed to flutamide at different days of pregnancy $v s$. controls. The ROD was measured as described in Material and methods. Statistically significant differences were analyzed by the Mann-Whitney U-test $(* p<0.05)$.

well as an increase in resistance index in pregnant rats leading to placental and fetal hypoxia [18]. Moreover, those placentas showed increased HIF-1 $\alpha$ level which may indicate on increased hypoxia. On the other hand several angiogenesis-related genes were down-regulated in rats with elevated testosterone [18]. Further experiments with microarray analysis using the rat model with elevated testosterone level revealed also changes in the expression of genes within the vascular development pathway among which, abnormal placental vascularization (which would tend to reduce oxygen delivery to placenta) and hypoxia were identified. Elevated testosterone level increased expression of genes known to disrupt vascular remodeling and induce endothelial cell apoptosis [30].

Angiogenesis and cell survival are regulated by a transcriptional complex composed of hypoxia inducible factors HIF- $1 \alpha$, HIF- $1 \beta$ and HIF- $2 \alpha$ which control expression of several genes. A consensus hypoxia responsive element (HRE) for HIF association is present in the 5' promoter region of the target genes including VEGFA, VEGFR-1 [31]. HIF- $1 \alpha$ is induced by hypoxia while HIF- $1 \beta$ is expressed constitutively. HIF- $1 \alpha$ is rapidly degraded by proteasomes during normoxia [32]. The role of hypoxia in the regulation of angiogenesis was demonstrated in mice with inactivated genes for $H I F-1 \alpha$ and $H I F-1 \beta$ [33]. HIF system is induced by many factors which lead to increase of transcription from VEGFA gene under hypoxic conditions. Finally, this induction results in an elevated level of VEGFA and its receptor [34].

VEGFA is an angiogenic factor regulated by tissue oxygen tension and exposure to low oxygen levels increases VEGFA mRNA levels [35]. Moreover, also other transcription factors involved in angiogenesis are activated in response to hypoxia [36]. A strong 
evidence for a role of VEGFA was obtained from the study on the conditional mouse model, which enabled the discovery that VEGF was essential for HIF- $1 \alpha$ mediated neovascularization but dispensable for endothelial sprouting [37].

Although more attention is paid to the processes which occur at the early pregnancy, the period of late pregnancy remains important for the final success of reproduction. Previously, we had demonstrated that antiandrogen flutamide affected expression of AR and Cx43 within placenta during late pregnancy $[9,16]$. Therefore, our current study further confirms that diminished androgen level during late pregnancy influences the expression of two important genes involved in the process of angiogenesis within porcine placenta. Signal transduction pathway may involve different factors responsible for the signal transfer.

Testosterone promotes the proliferation of human myometrial microvascular endothelial cells through the activation of the MAP/ERK-kinase pathway and VEGFA production [38]. Another model with prenatally androgenized sheep tries to explain cross-talk between AR and HIF- $1 \alpha$ focuses on the interaction between ligand-activated AR, growth factors (such as EGF) with their receptors and PI3K pathway [23]. Activation of HIF- $1 \alpha$ by androgen signaling drives the expression of genes involved in angiogenesis such as VEGF and in regulation of placentation as insulin-like growth factor 2 [IGF2]. On the other hand, a half-site for androgen response element (ARE) is localized in the promoter region of VEGF. Therefore, $\mathrm{AR}$ with its co-regulatory protein may form the complex, which directly regulates placental VEGF expression [23].

Our data suggest that flutamide binding to ARs could initiate reduction in HIF- $1 \alpha$ transcription as decreased mRNA level was noticed at $90 \mathrm{dpc}$ in pig placentas. Moreover, observed changes in the level of mRNA were followed by down-regulation in protein level and diminished immunostaining intensity for HIF- $1 \alpha$ and VEGFA protein. Therefore, we assume that hypoxia resulting from androgen withdrawal, was not sufficient to up-regulate HIF- $1 \alpha$ protein expression. Interestingly, both nuclear and cytoplasmic HIF- $1 \alpha$ immunostaining were observed in the present study. Berisha et al. also demonstrated the presence of nuclear and cytoplasmic localization of HIF- $1 \alpha$ in the bovine ovary [39]. Based on our previous experience showing nuclear AR immunolocalization within granulosa cells and cytoplasmic AR localization within corpus luteum on 90 day of gestation in pig [40], we assume that the nuclear and cytoplasmic staining may depend on the rate of the protein turnover. The presence of HIF- $1 \alpha$ protein in the cytoplasm may indicate either protein degradation or protein synthesis just before their transfer to the nucleus.
In summary, our data suggest that androgens are important factors regulating expression of HIF- $1 \alpha$ and VEGFA in porcine placenta during late pregnancy. The influence of androgens on placenta system may let to introduce them into therapy of some placenta dysfunctions during pregnancy.

\section{Acknowledgments}

This work was financially supported by K/ZDS/006308. The authors would like to thank Professor Marek Koziorowski (Department of Physiology and Reproduction of Animals, University of Rzeszow, Poland) for the valuable assistance in the handling of animals.

\section{Conflict of interest}

The authors declare that they have no conflict of interest.

\section{Authors' contribution}

EC and IW-R were involved in immunohistochemical analysis and data interpretation, KK-S and MG were involved in mRNA expression analysis and data interpretation, and MS contributed to conception and wrote the manuscript.

\section{References}

1. Maliqueo M, Echiburú B, Crisosto N. Sex steroids modulate uterine-placental vasculature: implications for obstetrics and neonatal outcomes. Front Physiol. 2016; 7: 152, doi: 10.3389/ /fphys.2016.00152, indexed in Pubmed: 27199767.

2. Wang Q, Shen L, Huang W, et al. Vasculogenesis of decidua side population cells of first-trimester pregnancy. Stem Cell Res Ther. 2013; 4(3): 50, doi: 10.1186/scrt200, indexed in Pubmed: 23651491.

3. Albrecht ED, Pepe GJ. Estrogen regulation of placental angiogenesis and fetal ovarian development during primate pregnancy. Int J Dev Biol. 2010; 54(2-3): 397-408, doi: 10.1387/ /ijdb.082758ea, indexed in Pubmed: 19876841.

4. Robb VA, Pepe GJ, Albrecht ED. Acute temporal regulation of placental vascular endothelial growth/permeability factor expression in baboons by estrogen. Biol Reprod. 2004; 71(5): 1694-1698, doi: 10.1095/biolreprod.104.030882, indexed in Pubmed: 15269101.

5. Corcoran JJ, Nicholson C, Sweeney M, et al. Human uterine and placental arteries exhibit tissue-specific acute responses to $17 \beta$-estradiol and estrogen-receptor-specific agonists. Mol Hum Reprod. 2014; 20(5): 433-441, doi: 10.1093/molehr/ /gat095, indexed in Pubmed: 24356876.

6. Cheng G, Weihua Z, Mäkinen S, et al. A role for the androgen receptor in follicular atresia of estrogen receptor beta knockout mouse ovary. Biol Reprod. 2002; 66(1): 77-84, doi: 10.1095/biolreprod66.1.77, indexed in Pubmed: 11751267.

7. Knapczyk-Stwora K, Grzesiak M, Duda M, et al. TGF $\beta$ (transforming growth factor $\beta$ ) superfamily members and their receptors in the fetal porcine ovaries: effect of prenatal flutamide treatment. Folia Histochem Cytobiol. 2014; 52(4): 317-325, doi: 10.5603/FHC.a2014.0033, indexed in Pubmed: 25410538. 
8. Hsu TY, Lan KC, Tsai CC, et al. Expression of androgen receptor in human placentas from normal and preeclamptic pregnancies. Taiwan J Obstet Gynecol. 2009; 48(3): 262-267, doi: 10.1016/S1028-4559(09)60301-6, indexed in Pubmed: 19797017.

9. Wieciech I, Durlej-Grzesiak M, Słomczyńska M. Influence of the antiandrogen flutamide on the androgen receptor gene expression in the placenta and umbilical cord during pregnancy in the pig. Acta Histochem. 2013; 115(3): 290-295, doi: 10.1016/j.acthis.2012.08.003, indexed in Pubmed: 22951468.

10. Khatri P, Hoffmann B, Schuler G. Androgen receptor is widely expressed in bovine placentomes and up-regulated during differentiation of bovine trophoblast giant cells. Placenta. 2013; 34(5): 416-423, doi: 10.1016/j.placenta.2013.01.018, indexed in Pubmed: 23481223.

11. James JL, Stone PR, Chamley LW. The regulation of trophoblast differentiation by oxygen in the first trimester of pregnancy. Hum Reprod Update. 2006; 12(2): 137-144, doi: 10.1093/humupd/dmi043, indexed in Pubmed: 16234296.

12. Wang GL, Jiang BH, Rue EA, et al. Hypoxia-inducible factor 1 is a basic-helix-loop-helix-PAS heterodimer regulated by cellular O2 tension. Proc Natl Acad Sci USA. 1995; 92(12): 5510-5514, doi: 10.1073/pnas.92.12.5510, indexed in Pubmed: 7539918.

13. Patel J, Landers K, Mortimer RH, et al. Regulation of hypoxia inducible factors (HIF) in hypoxia and normoxia during placental development. Placenta. 2010; 31(11): 951-957, doi: 10.1016/j.placenta.2010.08.008, indexed in Pubmed: 20869770.

14. Krock BL, Skuli N, Simon MC. Hypoxia-induced angiogenesis: good and evil. Genes Cancer. 2011; 2(12): 1117-1133, doi: 10.1177/1947601911423654, indexed in Pubmed: 22866203.

15. Zhou Y, McMaster M, Woo K, et al. Vascular endothelial growth factor ligands and receptors that regulate human cytotrophoblast survival are dysregulated in severe preeclampsia and hemolysis, elevated liver enzymes, and low platelets syndrome. Am J Pathol. 2002; 160(4): 1405-1423, doi: 10.1016/ /S0002-9440(10)62567-9, indexed in Pubmed: 11943725.

16. Wieciech I, Grzesiak M, Knapczyk-Stwora K, et al. Influence of the antiandrogen flutamide on connexin $43(\mathrm{Cx} 43)$ gene and protein expression in the porcine placenta and uterus during pregnancy. Folia Biol (Krakow). 2014; 62(4): 367-375, doi: 10.3409/fb62_4.367, indexed in Pubmed: 25916165.

17. Knapczyk-Stwora K, Grzesiak M, Duda M, et al. Effect of flutamide on folliculogenesis in the fetal porcine ovary - regulation by Kit ligand/c-Kit and IGF1/IGF1R systems. Anim Reprod Sci. 2013; 142(3-4): 160-167, doi: 10.1016/j.anireprosci.2013.09.014, indexed in Pubmed: 24139236.

18. Gopalakrishnan K, Mishra JS, Chinnathambi V, et al. Elevated testosterone reduces uterine blood flow, spiral artery elongation, and placental oxygenation in pregnant rats. Hypertension. 2016; 67(3): 630-639, doi: 10.1161/HYPERTENSIONAHA.115.06946, indexed in Pubmed: 26781277.

19. Santos TC, Oliveira MF, Papa PC, et al. VEGF system expression by immunohistochemistry and real-time RT-PCR study on collared peccary placenta. Theriogenology. 2014; 82(6): 834-843, doi: 10.1016/j.theriogenology.2014.06.016, indexed in Pubmed: 25087046.

20. Knapczyk-Stwora K, Belej A, Grzesiak M, et al. Effect of gestational antiandrogen treatment on Dicer1 expression in the porcine fetal gonads. Acta Histochem. 2015; 117(8): 725-731, doi: 10.1016/j.acthis.2015.09.002, indexed in Pubmed: 26433267.

21. Smolen AJ. Image analytic techniques for quantification of immunocytochemical staining in the nervous system. In: Conn
PM. ed. Methods in neurosciences. Academic Press, New York 1990: 208-229.

22. Pugh CW, Ratcliffe PJ. Regulation of angiogenesis by hypoxia: role of the HIF system. Nat Med. 2003; 9(6): 677-684, doi: 10.1038/nm0603-677, indexed in Pubmed: 12778166.

23. Cleys ER, Halleran JL, Enriquez VA, et al. Androgen receptor and histone lysine demethylases in ovine placenta. PLoS One. 2015; 10(2): e0117472, doi: 10.1371/journal. pone.0117472, indexed in Pubmed: 25675430.

24. Palacios S. Androgens and female sexual function. Maturitas. 2007; 57(1): 61-65, doi: 10.1016/j.maturitas.2007.02.014, indexed in Pubmed: 17368976.

25. Słomczyńska M, Duda M, Burek M, et al. Distribution of androgen receptor in the porcine uterus throughout pregnancy. Reprod Domest Anim. 2008; 43(1): 35-41, doi: 10.1111/j.1439-0531.2007.00849.x, indexed in Pubmed: 18199256.

26. Gao W, Kim J, Dalton JT. Pharmacokinetics and pharmacodynamics of nonsteroidal androgen receptor ligands. Pharm Res. 2006; 23(8): 1641-1658, doi: 10.1007/s11095-006-9024-3, indexed in Pubmed: 16841196.

27. Dean A, Smith LB, Macpherson S, et al. The effect of dihydrotestosterone exposure during or prior to the masculinization programming window on reproductive development in male and female rats. Int J Androl. 2012; 35(3): 330-339, doi: 10.1111/j.1365-2605.2011.01236.x, indexed in Pubmed: 22248293.

28. Morisset AS, Dubé MC, Drolet R, et al. Androgens in the maternal and fetal circulation: association with insulin resistance. J Matern Fetal Neonatal Med. 2013; 26(5): 513-519, doi: 10.3109/14767058.2012.735725, indexed in Pubmed: 23075231.

29. Battaglia C, Mancini F, Fabbri R, et al. Vascular risk in young women with polycystic ovary and polycystic ovary syndrome. Obstet Gynecol. 2008; 111(2 Pt 1): 385-395, doi: 10.1097/01. AOG.0000296657.41236.10, indexed in Pubmed: 18238977.

30. Fernandez EV, Reece KM, Ley AM, et al. Dual targeting of the androgen receptor and hypoxia-inducible factor $1 \alpha$ pathways synergistically inhibits castration-resistant prostate cancer cells. Mol Pharmacol. 2015; 87(6): 1006-1012, doi: 10.1124/mol.114.097477, indexed in Pubmed: 25829060.

31. Saharinen P, Eklund L, Pulkki K, et al. VEGF and angiopoietin signaling in tumor angiogenesis and metastasis. Trends Mol Med. 2011; 17(7): 347-362, doi: 10.1016/j. molmed.2011.01.015, indexed in Pubmed: 21481637.

32. Günter J, Ruiz-Serrano A, Pickel C, et al. The functional interplay between the HIF pathway and the ubiquitin system more than a one-way road. Exp Cell Res. 2017; 356(2): 152-159, doi: 10.1016/j.yexcr.2017.03.027, indexed in Pubmed: 28315321.

33. Samanta D, Semenza GL. Maintenance of redox homeostasis by hypoxia-inducible factors. Redox Biol. 2017; 13: 331-335, doi: 10.1016/j.redox.2017.05.022, indexed in Pubmed: 28624704

34. Schönenberger MJ, Kovacs WJ. Hypoxia signaling pathways: modulators of oxygen-related organelles. Front Cell Dev Biol. 2015; 3: 42, doi: 10.3389/fcell.2015.00042, indexed in Pubmed: 26258123.

35. Lazarus A, Keshet E. Vascular endothelial growth factor and vascular homeostasis. Proc Am Thorac Soc. 2011; 8(6): 508-511, doi: 10.1513/pats.201102-021MW, indexed in Pubmed: 22052928.

36. Elks PM, Renshaw SA, Meijer AH, et al. Exploring the HIFs, buts and maybes of hypoxia signalling in disease: lessons from zebrafish models. Dis Model Mech. 2015; 8(11): 1349-1360, doi: 10.1242/dmm.021865, indexed in Pubmed: 26512123. 
37. Oladipupo S, Hu S, Kovalski J, et al. VEGF is essential for hypoxia-inducible factor-mediated neovascularization but dispensable for endothelial sprouting. Proc Natl Acad Sci USA. 2011; 108(32): 13264-13269, doi: 10.1073/pnas.1101321108, indexed in Pubmed: 21784979.

38. Dietrich W, Gaba A, Zhegu Z, et al. Testosterone dependent androgen receptor stabilization and activation of cell proliferation in primary human myometrial microvascular endothelial cells. Fertil Steril. 2011; 95(4): 1247-12455, doi: 10.1016/j. fertnstert.2010.11.012, indexed in Pubmed: 21130428.
39. Berisha B, Schams D, Rodler D, et al. Expression pattern of HIF1alpha and vasohibins during follicle maturation and corpus luteum function in the bovine ovary. Reprod Dom Anim. 2016; 52(1): 130-139, doi: 10.1111/rda.12867.

40. Duda M, Burek M, Galas J, et al. Immunohistochemical localization of androgen receptor and aromatase in the ovary of the pregnant pig. Reprod Biol. 2004; 4(3): 289-298, indexed in Pubmed: 15592587.

Submitted: 14 July, 2017

Accepted after reviews: 2 October, 2017 Available as AoP: 9 October, 2017 